\title{
Layered Double Hydroxide Nanomaterial as Highly Efficient Adsorbent and its Recycling after Removal of a Carcinogenic Tartrazine Dye from Wastewater
}

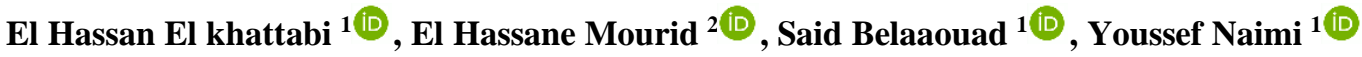 \\ 1 Materials Physics Chemistry Laboratory, Department of Chemistry, Faculty of Science- Ben M'SIK, Hassan II University \\ of Casablanca, Morocco \\ 2 Physical Chemistry of Materials Team, Cadi Ayyad University, Marrakech, Morocco \\ * Correspondence: eelkhattabi36@gmail.com (E.H.E.k.);
}

Scopus Author ID 55361408100 (E.H.E.k.)

Received: 2.10.2021; Revised: 1.11.2021; Accepted: 3.11.2021; Published: 28.11.2021

\begin{abstract}
In this work, the tartrazine dye is removed from the wastewater by the layered double hydroxide $(\mathrm{LDH})$ [ $\left.\mathrm{Zn}_{2}-\mathrm{Al}-\mathrm{Cl}\right]$. $\mathrm{LDH}$ materials have proven to be highly effective in removing pollutants, with a low cost of synthesis, non-toxic, and they do not regenerate the sludge. Several parameters were studied, the retention of dye by LDH nanomaterial is optimized for a $\mathrm{pH}$ between 6 and 8, the equilibrium retention is obtained after 24 hours, and retention kinetics follows the pseudosecond-order model. The isotherms are the $\mathrm{H}$ type, and they follow the Langmuir model, retention capacity reaches $100 \%$ for a mass ratio (adsorbate/adsorbent) between 0.1 and 0.5 , and the maximum amount retained of the dye is $740.35 \mathrm{mg} / \mathrm{g}$ for an initial concentration of tartrazine was $1200 \mathrm{mg} / \mathrm{L}$ and $100 \mathrm{mg}$ of mass of LDH. X-ray diffraction (XRD) showed that the synthesized matrix is crystallized in a lamellar structure. Two processes affect the removal of the dye, adsorption of the surface of LDH, and intercalation between the layers. Infrared analysis indicated the appearance of the band's dye in the spectrum of the matrix after retention. Moreover, scanning electron microscopy showed the lamellar character of the two phases obtained before and after retention. The thermodynamics study showed that the process is endothermic, and the adsorption mechanism is governed by physisorption. The LDH nanomaterial is a good adsorbent with low cost, high efficiency, and recyclable.
\end{abstract}

Keywords: layered double hydroxide; tartrazine; adsorption; intercalation; physisorption; recycling.

(c) 2021 by the authors. This article is an open-access article distributed under the terms and conditions of the Creative Commons Attribution (CC BY) license (https://creativecommons.org/licenses/by/4.0/).

\section{Introduction}

Along with the rapid development of industrialization, wastewater treatment has been considered a huge challenge over the past decades [1,2]. Heavy metal ions and organic compounds are often discharged together with industrial wastewater. Especially in the industries of metal coating, leather tanning, and petroleum refining [3].

Water pollution has become a major interest for public authorities; water pollution means all changes in the water's characteristics that are embarrassing or harmful to human uses, fauna, or flora. Water becomes depleted or enriched with substances of all kinds during its use or changes in temperature. The resulting pollution ends up in the natural environment. Dyes are used widely such as in textiles, tanning, food processing, paints, and cosmetics. The global production is estimated at 800.000 tonnes per year, of which 140.000 are released in effluents during the various stages of application and preparation [4]. However, industrial effluents containing dyes present many environmental problems, such as eutrophication, under- 
oxygenation, odor, persistence, bioaccumulation, mutagenicity, and carcinogenicity [5]. Azo dyes are the most used family characterized by an azo chromophore group $(-\mathrm{N}=\mathrm{N}-)$. The family of azo dyes is the most toxic, which its toxicity was already reported in 1895 by the increase of bladder cancer among workers in the textile industry [6]. Indeed several studies prove the carcinogenic effect of azo dyes for humans and animals [6-9]; indeed, the azo bond is a more labile bond of these substances, then the breaking of this azo by enzymatic action results in carcinogenic amine groups will be regenerated $[7,10,11]$. They represent more than $50 \%$ of the world's production of coloring matters and are divided into several categories: water-soluble basic, acidic, direct and reactive dyes, water-insoluble nonionic disperse, and mordant azo. It is estimated that at least $10-15 \%$ of the initial quantities are lost during the dyeing procedures and are discharged without prior treatment in the effluent [12]. However, these carcinogenic organic compounds are refractory to the treatment processes usually implemented and are very resistant to biodegradation.

Among the most toxic azo dyes is tartrazine (TAR) [7], a yellow synthetic azoic dye. It is used in many industries, such as food (E102 - Yellow 5 in the USA) and cosmetics (CI 19140). The detrimental effect of tartrazine on healthy sources of anxiety, hyperactivity, depression, and asthma [13,14]. Another study has confirmed that tartrazine dye has genotoxic effects [8]. In this context, some research focuses on eliminating tartrazine dye and Other toxic organic pollutants from wastewater by different treatment methods $[15,16]$. These methods include anion exchange resin removal [17], treatment by advanced oxidation processes such as Photo-Fenton [18], or by photo-catalytic through $\mathrm{TiO}_{2}$ [19], or treatment by electrocoagulation with electrochemical advanced oxidation processes [20]. However, these treatment methods are expensive, regenerate more toxic and unknown products, require high technology, and regenerate sludge. The adsorption method remains the most used because of its simplicity, efficiency, and low cost [21,22]. Several materials are used to remove tartrazine, such as activated carbon [23-25], chitin, chitosan [26], etc. Among them, we find a Layered double hydroxide $(\mathrm{LDH})$ nanomaterial, which has proven effective in eliminating many pollutants, so they are inexpensive, recyclable, non-toxic, and do not regenerate sludge [27]. Then in this context, this work aims to remove tartrazine dye from water using $\mathrm{LDH}$ material $\left[\mathrm{Zn}_{2}-\mathrm{Al}-\mathrm{Cl}\right]$. The LDH materials have proved high retention efficiency due to their anionic exchange capacity due to their lamellar structures, which can intercalate different anions in their interlamellar spaces [27]. Layered double hydroxides are the hydrotalcite type. They owe their names to the fact that when crushed, they look like talcum powder. Lamellar materials have been the subject of much research for more than 40 years. They result from the succession and stacking of layers, generally of inorganic nature, and the inter-sheet spaces can contain inorganic or organic entities. The general formula of $\mathrm{LDH}$ materials is expressed as $\left[\mathrm{M}^{\mathrm{II}}{ }_{1-}\right.$ $\left.{ }_{\mathrm{x}} \mathrm{M}^{\mathrm{III}}{ }_{\mathrm{x}}(\mathrm{OH})_{2}\right]^{\mathrm{x}+}\left[\left(\mathrm{X}^{\mathrm{m}-}{ }_{\mathrm{x} / \mathrm{m}}\right), \mathrm{nH}_{2} \mathrm{O}\right]^{\mathrm{x}-}$, where $\mathrm{M}^{\mathrm{II}}$ and $\mathrm{M}^{\mathrm{III}}$ are divalent. Trivalent metal cations that occupy octahedral sites in the hydroxide layers, $\mathrm{X}^{\mathrm{m}-}$ is an exchangeable anion located in the interlayer space between two hydroxide layers [28]. Lamellar double hydroxides (LDHs) have been the subject of great interest in recent years because of their simplicity of synthesis, their low cost, and their possibility of regeneration [29]. They exhibit several properties such as anionic exchange [30] and catalytic [31], or as a support for electrochemical catalysts, as well as in the field of environment, namely the treatment of polluted water by the retention of different types of pollutants [32].

This study aims to eliminate one of the residual pollutants (tartrazine) with high persistence in the aquatic environment. Several methods have been used, such as biological, 
catalysis, and adsorption. Our work aims to reduce wastewater contamination by an ecofriendly layered double hydroxide material; it is chosen for its higher efficiency, its recyclability, and the non-regeneration of sludge. The removal rate is high, and the remaining quantity is widely below the tolerance thresholds.

\section{Materials and Methods}

\subsection{Synthesis of precursor.}

For the synthesis of the LDH precursor, we used the co-precipitation method at constant $\mathrm{pH}$ [33]. The optimal conditions for the synthesis are: $\mathrm{pH}=9$, molar ratio $\mathrm{Zn} / \mathrm{Al}=2$ and the addition rate of the metal salts $\left(\mathrm{Zn}^{2+}, \mathrm{Al}^{3+}\right)$ is $3 \mathrm{ml} / \mathrm{h}$. The $\mathrm{pH}$ was maintained constant by the addition of a $(0.5 \mathrm{M})$ sodium hydroxide solution. The synthesis was carried out under a stream of $\mathrm{N}_{2}$ to avoid contamination by atmospheric $\mathrm{CO}_{2}$. The ripening time (72h) is a decisive step in obtaining a relatively good product. The precipitate is then separated by filtration and washed by decarbonized water to remove the residual electrolytes (sodium chloride) formed during the synthesis. The product is finally dried at room temperature and gives a powdery texture material.

\subsection{Characterization of adsorbent material.}

Characterization of the powder obtained by XRD (Figure 1) showed that the phase corresponds to a pure LDH [34].

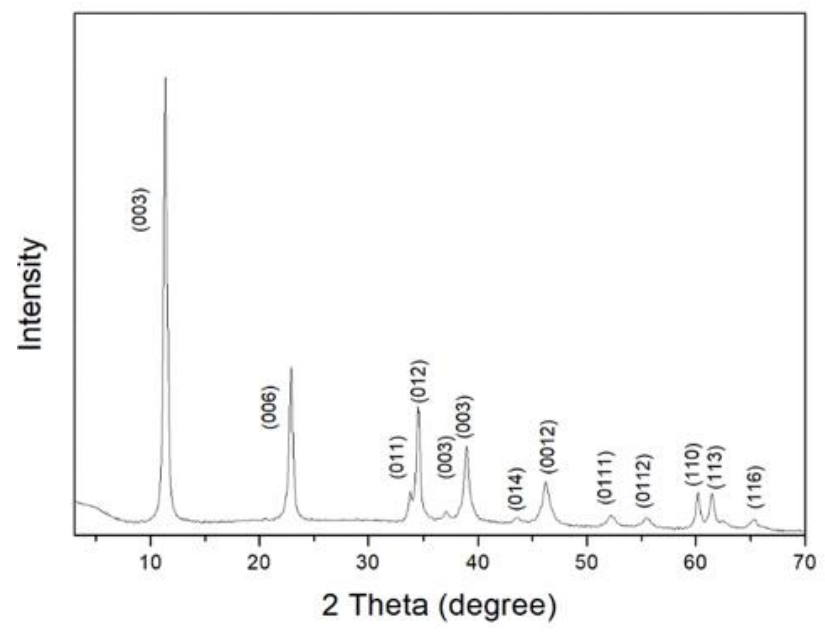

Figure 1. XRD pattern of $\left[\mathrm{Zn}_{2}-\mathrm{Al}-\mathrm{Cl}\right]$ precursor.

The solid consists of well-crystallized and single phases with large constituting crystallites. The spectrum of the XRD shows that our material adopts the rhombohedral crystal system, and the group of spatial symmetry is $\mathrm{R} \overline{3} \mathrm{~m}$. With the cell parameters: $\mathbf{a}=0.307 \mathrm{~nm}$; $\mathbf{c}$ $=2.322 \mathrm{~nm}$ and the distance " $\mathrm{d}$ " of $\mathrm{d}=\mathrm{c} / 3=0.774 \mathrm{~nm}$.

\subsection{Retention procedure.}

The retention tests are carried out at room temperature $\left(25^{\circ} \mathrm{C}\right)$, at constant $\mathrm{pH}$, maintained by adding $\mathrm{NaOH}$ and $\mathrm{HCl}$ solutions. Under a nitrogen atmosphere, the dispersion of the quantities of the adsorbent $\left[\mathrm{Zn}_{2}-\mathrm{Al}-\mathrm{Cl}\right]$ in $100 \mathrm{ml}$ of solutions of the Tartrazine dye prepared with decarbonated water. An initial concentration range of tartrazine varies between 50 and $1200 \mathrm{mg} / \mathrm{L}$. After filtration, the obtained solid products were dried at ambient 
temperature before being analyzed by the XRD technique. Moreover, the residual dye concentration was determined by UV-Vis spectroscopy. The absorbance was measured at 410 $\mathrm{nm}$ by a Jenway 6300 spectrophotometer. The retained amount $\mathrm{Q}(\mathrm{mg} / \mathrm{g})$ of the dye by $\left[\mathrm{Zn}_{2-}\right.$ $\mathrm{Al}-\mathrm{Cl}]$ was calculated by the following equation:

$$
Q=\frac{\left(C_{0}-C_{e}\right) \cdot V}{m}(1)
$$

where $\mathrm{C}_{0}$ is the initial concentration, $\mathrm{C}_{\mathrm{e}}$ is the concentration at equilibrium (final) of the solution dye, $\mathrm{m}$ is the mass of the adsorbent, and $\mathrm{V}$ is the volume of the solution.

\subsection{Analytical techniques.}

Samples of unoriented powder were exposed to the $\mathrm{K}_{\alpha}$ radiation of copper $(\lambda=0.15415$ $\mathrm{nm}$ ) in the apparatus of the Siemens D 501 diffractometer type used in X-ray diffraction. The measurements were taken under the following conditions: $2 \mathrm{~h}$ of the operation, with an angular range varied from 5 to $70^{\circ}$, step size: $0.08-2 \mathrm{~h}$, and step count of $4 \mathrm{~s}$. The acquisition of obtained data was performed on a microcomputer DACO-MP. We used a JASCO-6300 PC spectrophotometer for the infrared analysis, at a resolution of $2 \mathrm{~cm}^{-1}$ and with a regular of over 100 scans, in the range of 400 to $4000 \mathrm{~cm}^{-1}$ in wavenumbers, after the press of samples on $\mathrm{KBr}$ disks. Scanning electron microscopy (SEM) is one of the fundamental techniques for the characterization of materials, as it gives the morphology and topography data of the prepared samples. In addition, this technique can be used to determine the size of the pores in the case of porous materials. The SEM works similarly to an optical microscope, but electrons are used instead of light for this technique. A beam of concentrated electrons will be sent to the sample to be analyzed, and this will cause a release of secondary electrons. Subsequently, the electrons are collected by a detector and then analyzed to form an image.

\section{Results and Discussion}

Preliminary adsorption experiments were carried out to optimize the retention conditions of tartrazine on $\mathrm{LDH}$, such as the $\mathrm{pH}$ values of the solution, the contact time $\left(\mathrm{t}_{\mathrm{c}}\right)$, and the initial concentration $\left(\mathrm{C}_{\mathrm{i}}\right)$ of adsorbate and the mass ratio tartrazine/LDH.

\subsection{Chemical stability study of LDH.}

The final $\mathrm{pH}$ values as a function of the initial $\mathrm{pH}$ (Figure 2) showed the presence of a buffer zone where the $\mathrm{pH}$ is almost quasi-constant. The various initial $\mathrm{pH}$ values are calibrated by adding a few drops of $\mathrm{NaOH}$ or $\mathrm{HCl}$ solutions. The zero charge point $\mathrm{pH}$ (pHpzc) is where the final $\mathrm{pH}$ versus the initial $\mathrm{pH}$ curve crosses the lines $\mathrm{pH}_{\text {initial }}=\mathrm{pH}_{\text {final }}$. This point of intersection is pHpzc equal to 6.5.

This figure showed that the surface charge of LDH is almost neutral at pHpzc. At $\mathrm{pH}<$ pHpzc, the LDH surface has a net positive charge, while at $\mathrm{pH}>\mathrm{pHpzc}$ the surface has a net negative charge [35].

\subsection{Effect of $p H$.}

The $\mathrm{pH}$ of the mixture (solution of dye and matrix) influences the retention of tartrazine by the matrix. So, in our study, the desired $\mathrm{pH}$ was adjusted with $0.1 \mathrm{M}$ sodium hydroxide and hydrochloric acid solutions, with an initial concentration of tartrazine $\mathrm{C}_{0}=200 \mathrm{mg} / \mathrm{L}$. The 
mixtures were stirred at $48 \mathrm{~h}$ of contact time and filtered on the sintered glass; then, the filtrate was assayed by a UV-visible spectrophotometer. The result obtained is shown in Figure 3.

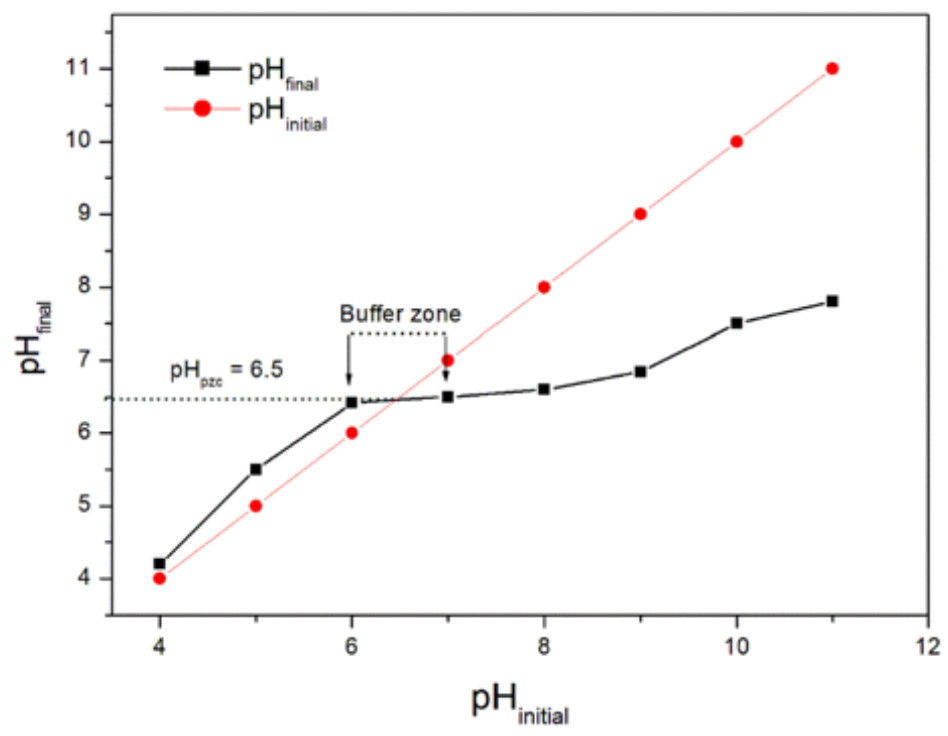

Figure 2. $\mathrm{pH}$ point of zero charges in the function of $\mathrm{pH}$ values.

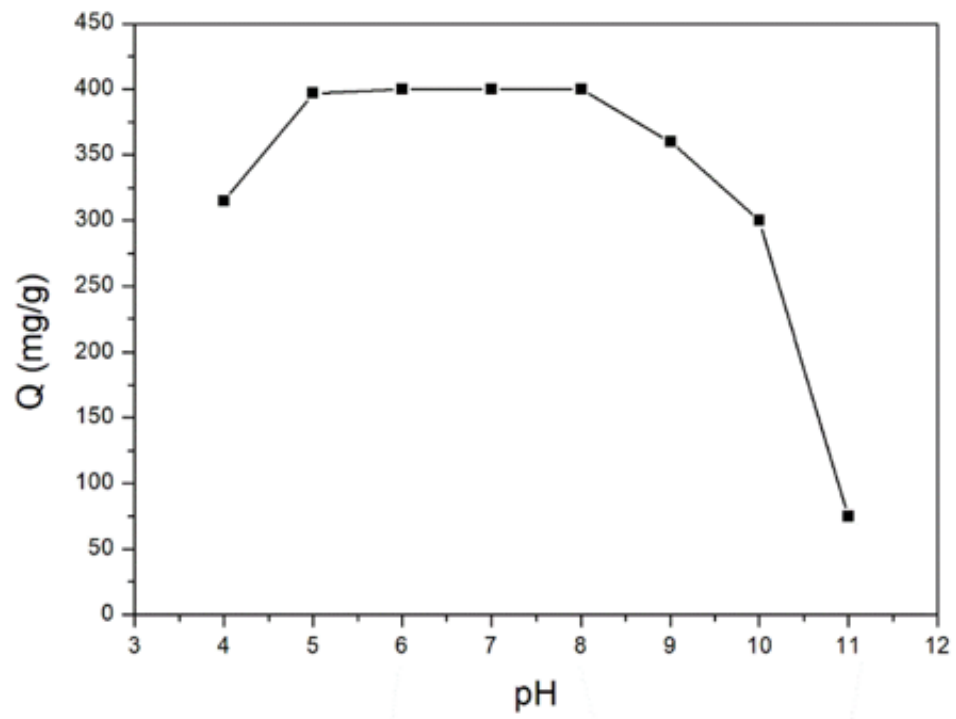

Figure 3. Retained amount of tartrazine by $\mathrm{LDH}\left[\mathrm{Zn}_{2}-\mathrm{Al}-\mathrm{Cl}\right]$ in the function of $\mathrm{pH}$.

From this figure, it can be concluded that the retention is favorable in $\mathrm{pH}$ between 6 and 8 . Then for a more acidic solution, there is a decrease in retention, which can be explained by partial dissolution of the matrix, and for a basic solution, the diminution in amount quantity due to the competition of the carbonate species that have a high affinity compared to tartrazine ions for $\mathrm{LDH}[33,34]$. Therefore, in the following, the $\mathrm{pH}$ will be fixed at 7.

\subsection{Kinetic studies.}

To follow the retention kinetics and optimize the dye-matrix contact time, the kinetics are followed in a time (Figure 4) interval up to $72 \mathrm{~h}$, for initial dye concentrations of 50, 200, 400 , and $800 \mathrm{mg} / \mathrm{L}$. The used mass of the matrix is $50 \mathrm{mg}$. 


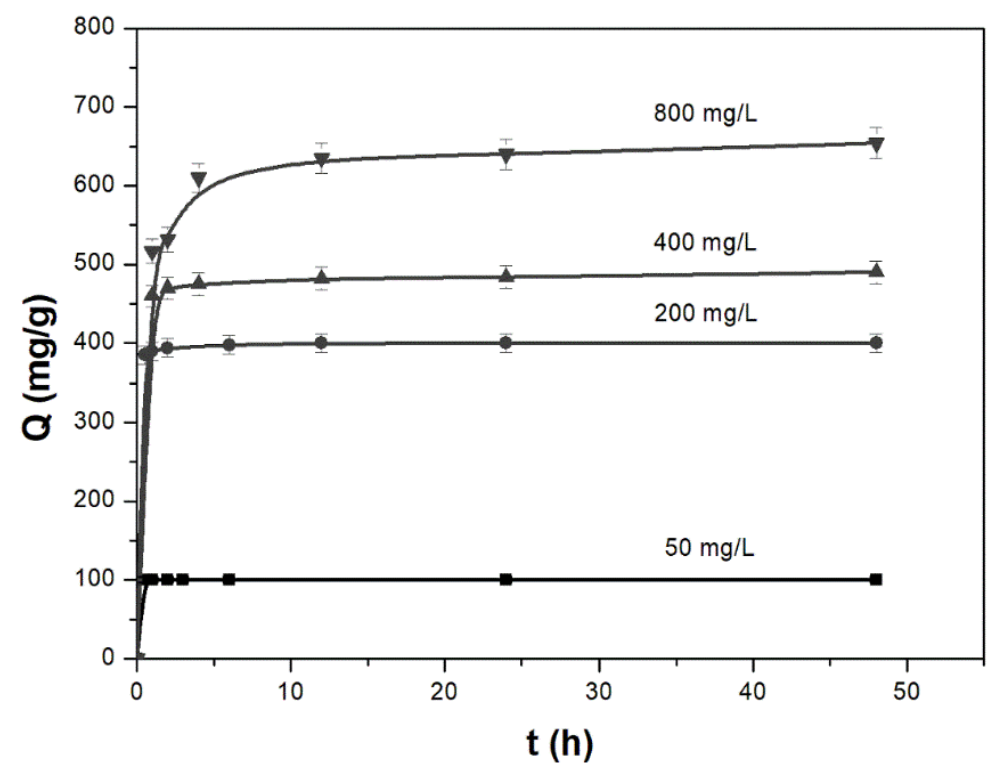

Figure 4. Adsorption kinetics of tartrazine by $\left[\mathrm{Zn}_{2}-\mathrm{Al}-\mathrm{Cl}\right]$.

From these results, it is observed that the process of retention of tartrazine by LDH [ $\left.\mathrm{Zn}_{2}-\mathrm{Al}-\mathrm{Cl}\right]$ is speed, the saturation is obtained in $1 \mathrm{~h}$ for $50 \mathrm{mg} / \mathrm{L}$, in $6 \mathrm{~h}$ for $200 \mathrm{mg} / \mathrm{L}$, in $24 \mathrm{~h}$ for 400 and $800 \mathrm{mg} / \mathrm{L}$.

Other studies have optimized this same equilibrium time to eliminate the herbicide 2,4$\mathrm{D}$ by the adsorbent material $\mathrm{Zn}_{2}-\mathrm{Al}-\mathrm{Cl}$ [24]. For low concentrations, the adsorption sites provided by the hydroxyl functions are accessible, and equilibrium is reached for a shorter time; on the other hand, there will be competition between the anions of the dye for high concentrations. This competition is delayed by electrostatic repulsion between the anions. Another phenomenon, which delays the achievement of the equilibrium, is the anionic exchange of chloride ions by the anions of the dye in the interlamellar space, which is a slow phenomenon [27]. The linear modeling according to the pseudo-second-order [35] and pseudofirst-order [36,37] models are given by the following equations:

$$
\begin{gathered}
\frac{t}{Q_{t}}=\frac{1}{k_{2} Q_{e}^{2}}+\frac{1}{Q_{e}} t(2) \\
\operatorname{Ln}\left(Q_{e}-Q_{t}\right)=\operatorname{Ln}\left(Q_{e}\right)-k_{1} \cdot t
\end{gathered}
$$

where $\mathrm{Q}_{\mathrm{e}}$ is the amount retained at equilibrium $(\mathrm{mg} / \mathrm{g}), \mathrm{Q}_{\mathrm{t}}$ is the amount withheld at a given time $(\mathrm{mg} / \mathrm{g}), \mathrm{k}_{2}$ is a kinetic constant of the pseudo-second-order $(\mathrm{g} / \mathrm{mg} / \mathrm{h})$, and with $\mathrm{k}_{1}$ is a kinetic constant of pseudo-first-order $\left(\mathrm{h}^{-1}\right)$.

The following table 1 shows the characteristics of the two models.

Table 1. Parameters of pseudo-first and pseudo-second-order models.

\begin{tabular}{c|c|c|c|c|c|c|c}
\multicolumn{4}{c|}{ Pseudo-first order } & \multicolumn{5}{c}{ Pseudo-second order } \\
\hline $\begin{array}{c}\text { C0 } \\
(\mathrm{mg} / \mathrm{L})\end{array}$ & $\begin{array}{c}\text { Qeth } \\
(\mathrm{mg} / \mathrm{g})\end{array}$ & $\begin{array}{c}\text { Qeexp } \\
(\mathrm{mg} / \mathrm{g})\end{array}$ & $\mathbf{R 2}$ & $\begin{array}{c}\mathbf{k 2} \\
(\mathrm{g} / \mathrm{mg} / \mathrm{h})\end{array}$ & $\begin{array}{c}\text { Qeth } \\
(\mathrm{mg} / \mathrm{g})\end{array}$ & $\begin{array}{c}\text { Qeexp } \\
(\mathrm{mg} / \mathrm{g})\end{array}$ & $\mathbf{R 2}$ \\
\hline 800 & 93.6 & 653.6 & 0.920 & 0.005 & 657.9 & 653.6 & 0.999 \\
\hline 400 & 31.2 & 498.8 & 0.815 & 0.009 & 500 & 498.8 & 0.999 \\
\hline 200 & 6 & 400 & 0.734 & 0.2 & 400 & 400 & 0,999 \\
\hline 50 & 0.3 & 100 & 0.625 & 5 & 100 & 100 & 1
\end{tabular}

From these results, it is concluded that the retention kinetics of the tartrazine dye is in good agreement with the pseudo-second-order model and that the constant $\mathrm{k}_{2}$ decreases with the increase in the initial concentration of tartrazine. 


\subsection{Intra-particle diffusion.}

To obtain an idea of the different processes of diffusion of the adsorbate towards the adsorbent, Figure 5 shows the adsorption capacity as a function of the square root of time according to the following equation:

$$
\mathrm{Q}_{\mathrm{t}}=\mathrm{K}_{\mathrm{id}} \mathrm{t}^{1 / 2}+\mathrm{C}(4)
$$

where, $K_{\text {id }}$ is the intraparticle diffusion rate constant $\left(\mathrm{mg} / \mathrm{g} / \mathrm{h}^{1 / 2}\right)$, and $\mathrm{C}(\mathrm{mg} / \mathrm{g})$ is a constant that gives an indication of the thickness of the boundary layer.

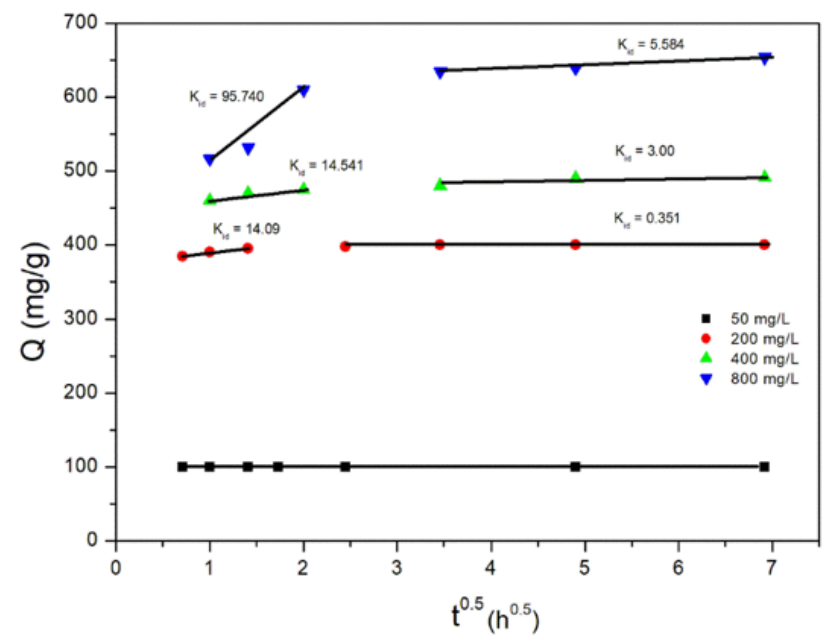

Figure 5. Intra-particle diffusion kinetic for adsorption of tartrazine onto LDH.

For the high concentrations ( 200 to $800 \mathrm{mg} / \mathrm{L}$ ), there are two processes. The first phase is due to external diffusion, while the second is related to the diffusion in the interlamellar space. This state indicates the reaching of equilibrium. This phase, accompanied by intercalation of the dye between the LDH sheets, will correspond to intra-particle diffusion. For the low concentration $(50 \mathrm{mg} / \mathrm{L})$, it is noticed that the external diffusion is fast, and the equilibrium state was reached rapidly. In this concentration, the phenomenon of intra-particle diffusion is absent.

\subsection{Adsorption isotherms.}

The adsorption isotherms let us know the maximum retention amount and the adsorption behavior (Figure 6). The study was realized with an initial concentration range from 50 to $1200 \mathrm{mg} / \mathrm{L}$ and four different $\mathrm{LDH}$ doses of 30, 50, 80, and $100 \mathrm{mg}$.

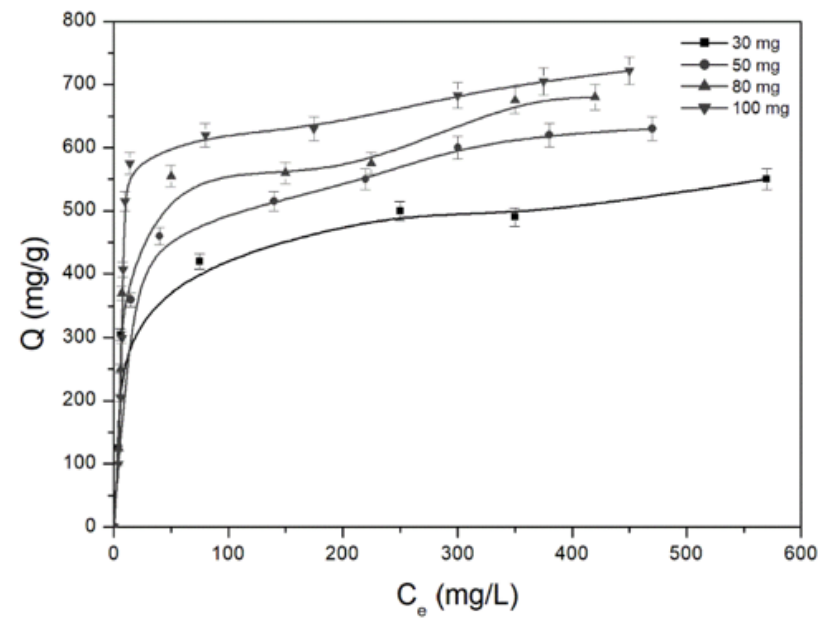

Figure 6. Adsorption isotherms of tartrazine onto LDH at different adsorbent doses. 
It can be noticed that isotherms of retention are of $\mathrm{H}$ type [38]. Initial parts of the isotherms are almost vertical; indicating that the interaction between the adsorbed molecules and the solid's surface is more rigid; the solvent-adsorbent interaction is much weaker than the adsorbate-adsorbent. The profile of isotherms is characteristic of systems where the ion-ion interactions between the functional groups of the adsorbate are robust, and the saturation is explained by the presence of a plateau, which shows that the tartrazine anions are eliminated almost completely from the aqueous medium [39].

The linearization of Langmuir [40] and Freundlich [41] models are given in the following equations:

$$
\begin{gathered}
\frac{C_{e}}{Q}=\frac{1}{K \cdot Q_{m}}+\frac{C_{e}}{Q_{m}}(5) \\
\operatorname{Ln}(Q)=\operatorname{Ln}\left(K_{F}\right)+\frac{1}{n} \operatorname{Ln}\left(C_{e}\right)
\end{gathered}
$$

Table 2 shows the parameters of the Langmuir and Freundlich models.

Table 2. The parameters of Langmuir and Freundlich models. Langmuir isotherm Freundlich isotherm

\begin{tabular}{c|c|c|c|c|c|c|c}
\hline $\begin{array}{c}\mathbf{m L D H} \\
(\mathrm{mg})\end{array}$ & $\begin{array}{c}\text { Qexp } \\
(\mathrm{mg} / \mathrm{L})\end{array}$ & $\begin{array}{c}\text { Qth } \\
(\mathrm{mg} / \mathrm{L})\end{array}$ & $\begin{array}{c}\mathbf{K} \\
(\mathrm{L} / \mathrm{mg})\end{array}$ & $\mathbf{R 2}$ & $\begin{array}{c}\mathbf{K f} \\
(\mathrm{mg} / \mathrm{g})\end{array}$ & $\mathbf{N}$ & $\mathbf{R 2}$ \\
\hline 30 & 571 & 565 & 0.11 & 0.997 & 230.4 & 7 & 0.992 \\
\hline 50 & 653.6 & 645.2 & 0.13 & 0.998 & 368.7 & 11.2 & 0.913 \\
\hline 80 & 705.6 & 685 & 0.15 & 0.996 & 397 & 11.5 & 0.853 \\
\hline 100 & 740.35 & 730 & 0.18 & 0.998 & 427.5 & 11.9 & 0.931
\end{tabular}

The result obtained shows an increase in the maximum amount with the mass of LDH adsorbent and achieves $740.35 \mathrm{mg} / \mathrm{g}$. The four isotherms were described by the Langmuir model, which explains why the surface of the LDH is homogeneous. The LDH is homogeneous, and the adsorption is done in monolayer; the value of the constant $\mathrm{K}$ is the same for the four isotherms, reflecting the nature of the (adsorbate/adsorbent) interaction is the same [27].

\subsection{Effect of the mass ratio (adsorbateladsorbent).}

Figure 7 shows the influence of the mass ratio (adsorbate/adsorbent) on the elimination rate; we used a dose of $50 \mathrm{mg}$ of $\mathrm{LDH}$ material with an initial concentration range of tartrazine varying from 50 to $800 \mathrm{mg} / \mathrm{L}$. From this curve, the elimination of tartrazine takes place at a mass ratio of between 0.1 and 0.5 . To optimize the mass of the LDH used while maintaining the total removal, it is of interest to use the largest ratio and the mass of the smallest doses of $\mathrm{LDH}$. Then for a given tartrazine concentration, the necessary matrix mass is determined for a total elimination by a mass ratio of 0.5 .

A decrease in the retention percentage is noted for the high (adsorbate/adsorbent) ratios with a constant mass of LDH adsorbent. This can be explained that at high concentrations of tartrazine, there is a competition between the anions of the dye towards the free sites of adsorption; this competition is delayed by electrostatic repulsion between these anions [42]. 


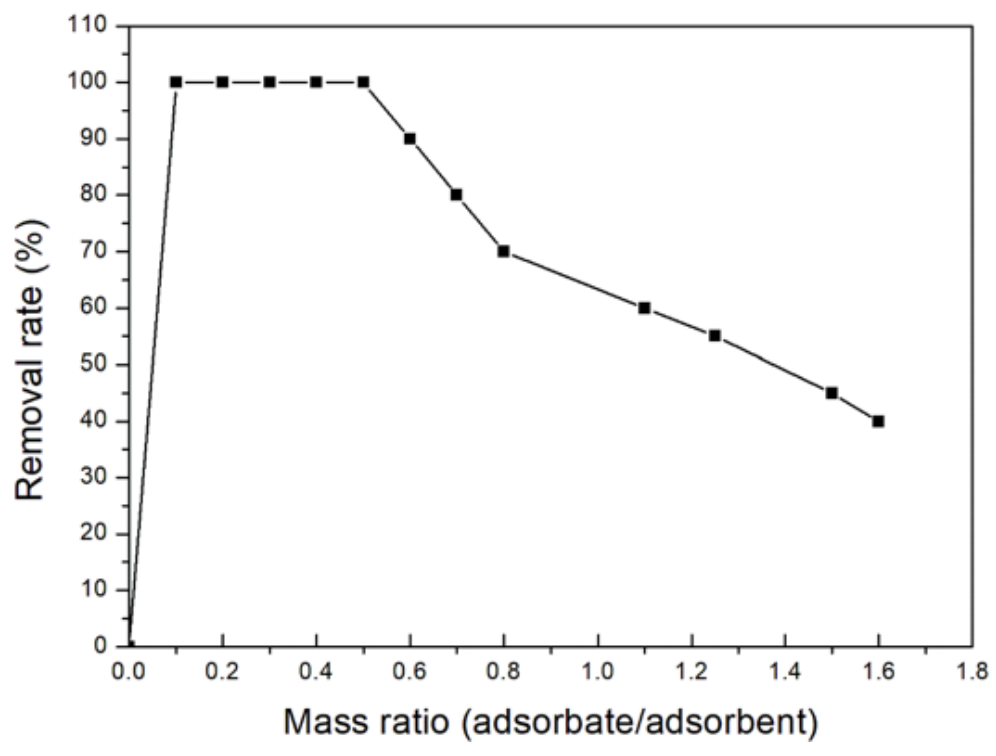

Figure 7. Effect of mass ratio (adsorbate/adsorbent) on the removal rate.

\subsection{Adsorption and intercalation of tartrazine.}

\subsubsection{Characterization by X-ray diffraction.}

It can be clearly seen that for low mass ratio (adsorbate/adsorbent) $(\mathrm{R}=0.1)$, the lines of the matrix before and after the retention of tartrazine are the same (Figure 8), this can be explained by the adsorption of the dye on the LDH surface. Whereas, from a high mass ratio $(\mathrm{R}=3)$, the line (003) shifts to the low values of $2 \theta$ at $3.8^{\circ}$. This result is similar to that of other work with $\mathrm{LDH}\left[\mathrm{Mg}_{3}-\mathrm{Al}-\mathrm{TAR}\right][43,44]$, which explains the increase in the inter-foliar distance from $\mathrm{d}=0.777 \mathrm{~nm}$ to $\mathrm{d}=2.25 \mathrm{~nm}$ due to the interchange of interlamellar $\mathrm{Cl}^{-}$ions with the larger tartrazine anions.

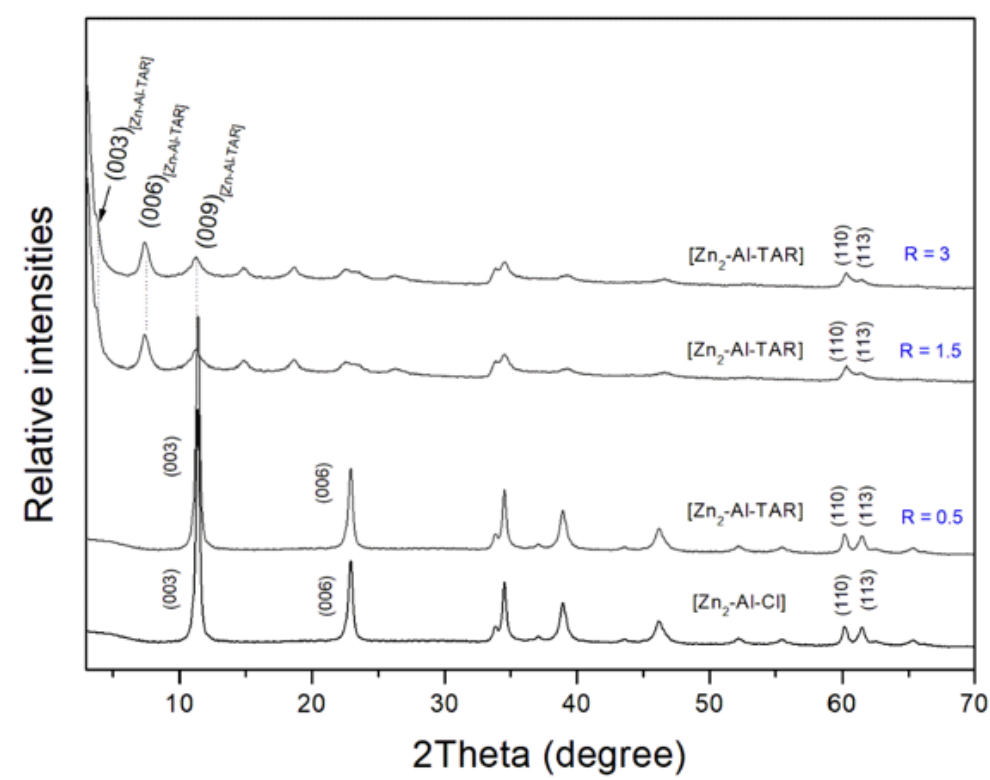

Figure 8. XRD patterns of the phases obtained after retention of tartrazine at three mass ratios.

Following these results, it can be concluded that two processes affect the removal of the dye tartrazine, adsorption for low mass ratio (adsorbate/adsorbent) and adsorption and intercalation for high mass ratio. The interlayer distance of our LDH increases from $0.777 \mathrm{~nm}$ 
to $2.25 \mathrm{~nm}$ after the intercalation of the tartrazine. Knowing that the thickness of the brucite layers is equal to $\mathrm{e}=0.21 \mathrm{~nm}$, the hydrogen bond has a distance of $0.27 \mathrm{~nm}$, and the length of the molecule of tartrazine is $1.8 \mathrm{~nm}$ [26]; if we add these distances, we will have a value greater than $2.25 \mathrm{~nm}$ found experimentally by XRD. Before proposing an orientation of the tartrazine anion between the sheets, we determined the value of the length of the tartrazine molecule using the molecular orbital semi-empirical method with Gaussian 03 software; the calculated value for an inclined orientation is $1.8 \mathrm{~nm}$.

Then we can explain this result by the fact that the anion representing tartrazine was not intercalated vertically, but it is interposed a little inclined by $34^{\circ}$. This result was found in another work [43] with an interlayer distance $d=2.30 \mathrm{~nm}$ close to our result $d=2.25 \mathrm{~nm}$. Therefore, an orientation of the tartrazine anions between the sheets LDH enables us to propose the schematic representation for phase $\left[\mathrm{Zn}_{2}-\mathrm{Al}-\mathrm{TAR}\right]$ in Figure 9.

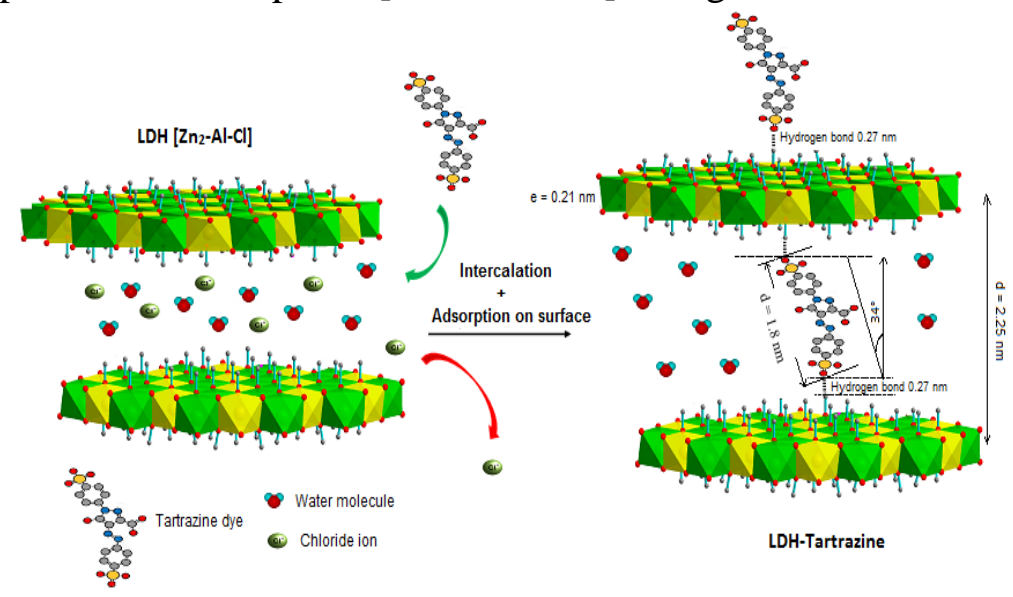

Figure 9. Schematic representation proposed for phase [ $\left.\mathrm{Zn}_{2}-\mathrm{Al}-\mathrm{TAR}\right]$.

The sorption mechanism between the pollutant in anionic form and the LDH adsorbent material is affected by the presence of hydrogen bonds between the sulphonate groups of tartrazine and the $\mathrm{OH}$ groups of the $\mathrm{LDH}$ sheet. It can be concluded that the retention of tartrazine can be affected by hydrogen bonds through electrostatic interactions. This retention is affected by two processes: adsorption on the surface and intercalation between the sheets of LDH [45].

\subsubsection{Study by infrared spectroscopy.}

Figure 10 shows the FT-IR spectra for Tartraine-LDH. This technique allows demonstrating the presence of the vibration bonds of the tartrazine compound and their interaction with the bonds of the LDH nanomaterial.

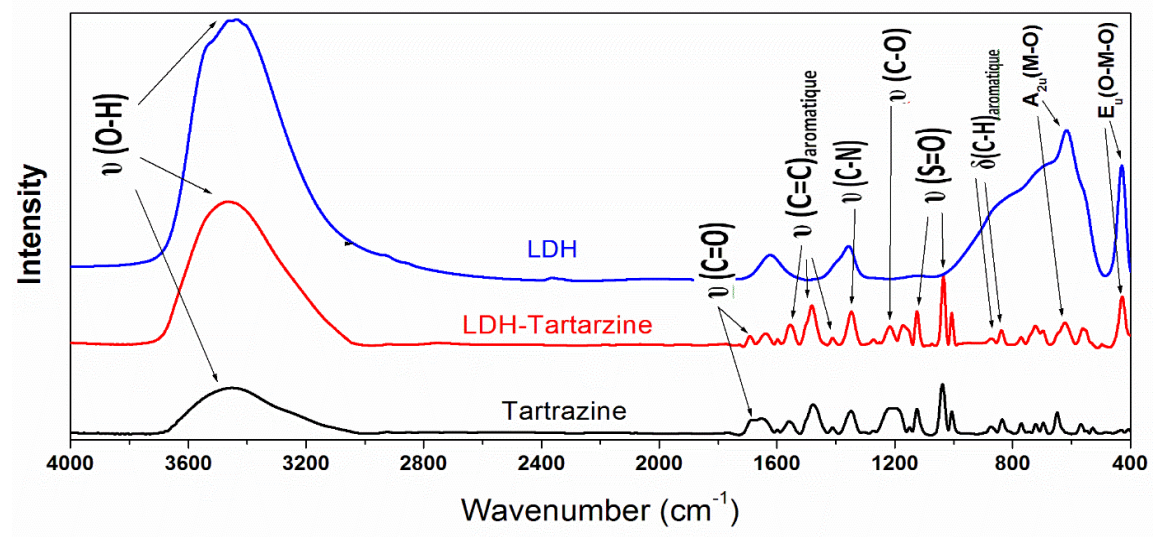

Figure 10. IR spectra of tartrazine dye, LDH-tartrazine, and LDH phase. 
It is noted that most IR bands of tartrazine appear in the spectrum of the phase obtained after dye retention, such as the broadband at $3400 \mathrm{~cm}^{-1}$ that corresponds to the $\mathrm{OH}$ valence vibrations, the characteristic bands of tartrazine at about $1500 \mathrm{~cm}^{-1}$ which corresponds to the vibrations of the $\mathrm{C}=\mathrm{C}$ bands of the benzene ring, vibrations about 1000 and $1200 \mathrm{~cm}^{-1}$ that corresponds to the asymmetric and symmetrical vibrations of the sulfonate groups $\mathrm{S}=\mathrm{O}$, the bands between 700 and $800 \mathrm{~cm}^{-1}$ that corresponds to the vibrations $(\mathrm{C}-\mathrm{H})$ of deformation outside benzene. The shape of this IR spectrum confirms that our dye was well retained by the matrix LDH.

\subsubsection{Study by Scanning Electron Microscopy.}

Figure 11 shows the SEM, which allows us to have information on the morphology of our material before and after retention of the tartrazine dye. SEM images are obtained with a magnification of 20.000 times.
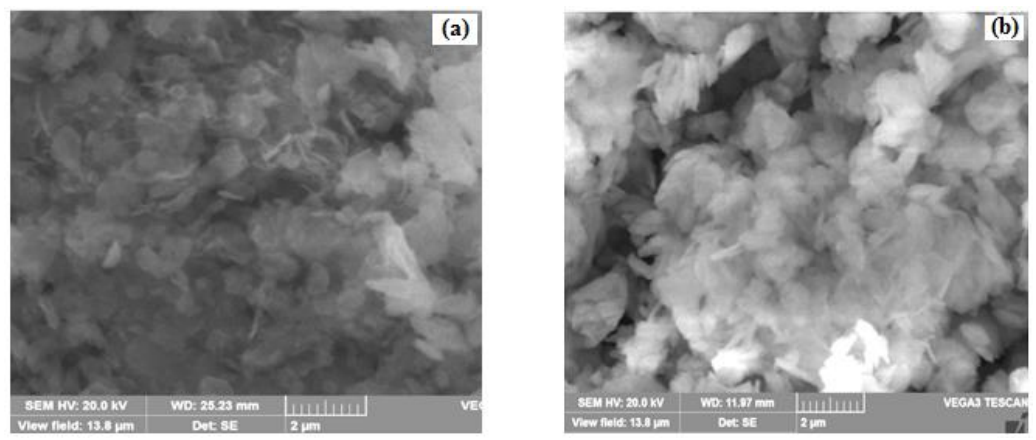

Figure 11. SEM images of phases (a) before and (b) after retention of tartrazine dye by LDH.

We can see the lamellar character of our material, with crystallites that can go up to 1 $\mu \mathrm{m}$. The lamellar character is slightly lowered after the dye's retention, which is justified by the results of XRD.

\subsection{Comparative study.}

The adsorption method has shown its effectiveness compared to other methods that have known many inconvenient. Several adsorbents are tested to remove pollutants from wastewater (activated carbon, food waste, and cationic clays, $\mathrm{LDH}$ ) to compare their retention efficiency with the maximum amount of retention and their rate of pollutant removal with our material.

Table 3. Removal rate and amount retained at the equilibrium of tartrazine by different materials.

\begin{tabular}{l|c|c|c}
\multicolumn{1}{c|}{ Materials } & Qm $(\mathrm{mg} / \mathrm{g})$ & Removal rate $(\%)$ & References \\
\hline Activated carbon of Lantana camara & 90.90 & 99.2 & {$[24]$} \\
\hline Saw dust & 4.71 & 97 & {$[35]$} \\
\hline Ni-doped ZnO nanoparticles & 22.5 & 99 & {$[46]$} \\
\hline Chitosan & 350 & 95 & {$[26]$} \\
\hline Cross-linked chitosan coated bentonite & 294.1 & 98 & {$[47]$} \\
\hline Polyanilinenano layer composite & 2.47 & 98 & {$[48]$} \\
\hline Hen feather & 6.41 & 100 & {$[49]$} \\
\hline Bottom ash & 12.6 & 100 & {$[50]$} \\
\hline Deoiled soya & 24.6 & 100 & {$[51]$} \\
\hline polystyrene resin anion exchange & 49.96 & - & {$[17]$} \\
\hline $\begin{array}{l}\text { Organo-Bentonite } \\
\text { Triethylenetetramine biochar }\end{array}$ & 40.79 & 98 & {$[52]$} \\
\hline LDH [Zn2-AI-Cl] & $\mathbf{7 4 0 . 3 5}$ & $\mathbf{1 0 0}$ & This work
\end{tabular}


It is observed that the LDH has a higher retained amount of the dye than other adsorbents with a removal rate of $100 \%$ (Table 3).

We can also compare the cost of synthesis, the regeneration of sludge, recycling. LDH does not regenerate sludge-like food waste, the cost of synthesis is relatively less than the cost of other materials, and in addition, they are recyclable by anion exchange reactions.

\subsection{Thermodynamic study.}

The maximum quantity retained at equilibrium is influenced by the temperature, which is an important thermodynamic factor, and then to determine the thermodynamic parameters of retention of tartrazine by $\mathrm{LDH}\left[\mathrm{Zn}_{2}-\mathrm{Al}-\mathrm{Cl}\right]$, in a thermostat, which adjusted three temperatures 303, 313, and $333 \mathrm{~K}$. For an initial concentration of tartrazine of $400 \mathrm{mg} / \mathrm{L}$ and a mass of the matrix of $50 \mathrm{mg}$, we determined the concentration $\mathrm{C}_{\mathrm{e}}$ at equilibrium and the maximum quantity retained at $\mathrm{Q}_{\mathrm{e}}$ equilibrium.

According to these four equations, we determined the thermodynamic parameters such as $\Delta \mathrm{S}^{\circ}, \Delta \mathrm{G}^{\circ}$ and $\Delta \mathrm{H}^{\circ}[53]$ :

$$
\begin{gathered}
k_{d}=\frac{Q_{e}}{C_{e}}(7) \\
\Delta G^{0}=-R \cdot T \cdot \ln \left(k_{d}\right)(8) \\
\ln \left(k_{d}\right)=\left(\frac{\Delta S^{0}}{R}\right)-\left(\frac{\Delta S^{0}}{R}\right) \cdot \frac{1}{T}
\end{gathered}
$$

where $\mathrm{k}_{\mathrm{d}}$ : distribution constant; $\mathrm{Q}_{\mathrm{e}}$ : adsorption capacity at equilibrium $(\mathrm{mg} / \mathrm{g}) ; \mathrm{C}_{\mathrm{e}}$ : equilibrium concentration of solute in solution $(\mathrm{mg} / \mathrm{L})$; R: the ideal gas constant $(\mathrm{J} / \mathrm{mol} / \mathrm{K})$ and $\mathrm{T}$ : absolute temperature $(\mathrm{K})$. The thermodynamic parameters are presented in Table 4.

Table 4. Thermodynamic parameters of retention.

\begin{tabular}{c|c|c|c}
$\mathbf{T}(\mathbf{K})$ & $\begin{array}{c}\Delta \mathbf{G}^{\circ} \\
(\mathrm{J} / \mathrm{mol})\end{array}$ & $\begin{array}{c}\Delta \mathbf{H}^{\circ} \\
(\mathrm{kJ} / \mathrm{mol})\end{array}$ & $\begin{array}{c}\Delta \mathbf{S}^{\circ} \\
(\mathrm{J} / \mathrm{mol} / \mathrm{K})\end{array}$ \\
\hline 303 & -3566.56 & & \\
\hline 313 & -4365.39 & 16.42 & 66.15 \\
\hline 323 & -5571.98 & &
\end{tabular}

The results show that the retention capacity increases by increasing the temperature, so the retention is endothermic. The negative value of $\Delta \mathrm{G}^{\circ}$ clearly confirms the spontaneous behavior of fixation. We note an increase in $\Delta \mathrm{G}^{\circ}$ with temperature, which clearly shows that the adsorption mechanism is more favorable at high temperatures.

The value of $\Delta \mathrm{H}^{\circ}<20 \mathrm{~kJ} / \mathrm{mol}$ indicates that the adsorption of tartrazine dye onto LDH is governed by physisorption interaction [53].

\subsection{Reuse and recycling study.}

The mass ratio (adsorbate/adsorbent) is a major factor in removing tartrazine by LDH, which is why we have used a mass ratio (adsorbate/adsorbent) of 0.5 , which gives maximum adsorption reaching $100 \%$. In order to exchange tartrazine ions with carbonate ions, we thought to create this exchange with a solution containing $1 \mathrm{M}$ of $\mathrm{Na}_{2} \mathrm{CO}_{3}$; these carbonates are very stable in the interlayer space due to the different affinities towards $\mathrm{LDH}$ sheets. The expression of removal of tartrazine is as follows: 
$\%$ Removal rate $=100\left(\mathrm{C}_{\mathrm{i}}-\mathrm{C}_{\mathrm{e}}\right) / \mathrm{C}_{\mathrm{i}}(10)$

with $\mathrm{C}_{\mathrm{e}}$ and $\mathrm{C}_{\mathrm{i}}$ being the equilibrium and initial tartrazine concentrations, respectively.

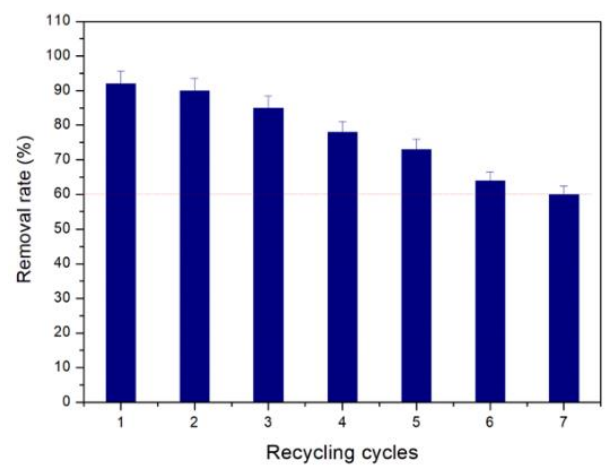

Figure 12. Recycling efficiency of LDH after removal of tartrazine for a mass ratio of 0.5.

After the exchange, the percentage of tartrazine removal from the different solutions decreases from 92 to $60 \%$ after seven recycling cycles (Figure 12). Therefore, we can say that the $\mathrm{LDH}$ precursor is a good material with low cost, high elimination rate, and is recyclable.

\section{Conclusions}

The results of the study of the retention of the dye tartrazine by $\mathrm{LDH}\left[\mathrm{Zn}_{2}-\mathrm{Al}-\mathrm{Cl}\right]$ allow us to conclude that: Retention is favored in media with a pH between 6 and 8, which favors the elimination of tartrazine from wastewater in natural media. The adsorption isotherms are of $\mathrm{H}$ type, which reflects the high affinity between the adsorbate and the adsorbent. The removal rate reaches $100 \%$ for an optimal mass ratio (adsorbate/adsorbent) equal to 0.5 with a maximum quantity of $740.35 \mathrm{mg} / \mathrm{g}$. The results of the characterization techniques show that two processes are adsorption on the surface and intercalation between the LDH sheets. The mechanism of adsorption is governed by physisorption interaction. The experimental results lead us to propose an inclined orientation of the tartrazine dye between the LDH sheets. The LDH nanomaterial is a good adsorbent with low cost, high efficiency, and is recyclable.

\section{Funding}

This research received no external funding.

\section{Acknowledgments}

This research has no acknowledgment.

\section{Conflicts of interest}

The authors declare no conflict of interest.

\section{References}

1. Pandey, S.; Yeon Do, J.; Kim, J.; Kang, M. Fast and highly efficient catalytic degradation of dyes using $\kappa-$ carrageenan stabilized silver nanoparticles nanocatalyst. Carbohydrate polymers 2020, 230, 11559, http://doi.org/10.1016/j.carbpol.2019.115597.

2. Pandey, S.; Ramontja, J. Natural bentonite clay and its composites for dye removal: current state and future potential. American Journal of Chemistry and Applications 2016, 3. 
3. Pandey, S.; Fosso-Kankeu, E.; Redelinghuys, J.; Kim, J.; Kang, M. Implication of biofilms in the sustainability of acid mine drainage and metal dispersion near coal tailings. Science of The Total Environment 2021, 788, 147851, https://doi.org/10.1016/j.scitotenv.2021.147851.

4. Hassaan, M. A.; El Nemr, A. Health and Environmental Impacts of Dyes: Mini Review. American Journal of Environmental Science and Engineering 2017, 3, 64-67, http://doi.org/10.11648/j.ajese.20170103.11.

5. Mansour, H.; Boughzala, O.; Dridi, d.; Barillier, D.; Chekir-Ghedira, L.; Mosrati, R. Les colorants textiles sources de contamination de l'eau : CRIBLAGE de la toxicité et des méthodes de traitement. Revue des sciences de l'eau / Journal of Water Science 2011, 24, 209-238, https://doi.org/10.7202/1006453ar.

6. Revathi, K.; Puvaneswari, N.; Rameshkumar, N.; Kayalvizhi, N. Urinary bladder cancer with focus on occupational dye workers. International Journal of Applied Biology and Pharmaceutical 2015, 6, 74-79.

7. Amchova, P.; Kotolova, H.; Ruda-Kucerova, J. Health safety issues of synthetic food colorants. Regulatory Toxicology and Pharmacology 2015, 73, 914-922, http://doi.org/10.1016/j.yrtph.2015.09.026.

8. Combes, R.D.; Haveland-Smith, R.B. A review of the genotoxicity of food, drug and cosmetic colours and other azo, triphenylmethane and xanthene dyes. Regulatory Toxicology and Pharmacology 1982, 98, 2, 249324, http://doi:10.1016/0165-1110(82)90015-x.

9. Brown M.A.; Devito, S.C. Predicting azo dye toxicity. Critical Reviews in Environmental Science and Technology 1993, 23, 405- 414, http://doi.org/10.1080/10643389309388453.

10. Bafana, A.; Devi, S.S.; Chakrabarti, T. Azo dyes: past, present and the future. Environmental Reviews 2011, 19, 350-370, https://doi.org/10.1139/a11-018.

11. Gupta, V.; R.Jain, K.; Shrivastava, M.; Nayak, A. Equilibrium and Thermodynamic Studies on the Adsorption of the Dye Tartrazine onto Waste "Coconut Husks" Carbon and Activated Carbon. Journal of Chemical \& Engineering Data 2010, 55, 5083-5090, https://doi.org/10.1021/je100649h.

12. Bauer, C.; Jacques, P.; Kalt, A. Photooxidation of an azo dye induced by visible light incident on the surface of TiO2. J. Photochem. Photobiol. A Chem. 2001, 140, 87-92, http://doi.org/10.1016/S1010-6030(01)003914.

13. Kamel, M.M.; El-lethey, H.S. The Potential Health Hazard of Tartrazine and Levels of Hyperactivity, Anxiety-Like Symptoms, Depression and Anti-social behaviour in Rats. Journal of American Science 2011, 7.

14. Rowe, K.S.; Rowe, K.J. Synthetic food coloring and behavior: A dose response effect in a double blind, placebo-controlled, repeated-measures study. Journal of Pediatrics 1994, 135, 691-698, http://doi.org/10.1016/s0022-3476(94)70059-1.

15. Liu, X.; Pang, H.; Liu, X.; Li, Q.; Zhan, N.; Mao, L.; Qiu, M.; Hu, B.; Yang, H.; Wang, X. Orderly Porous Covalent Organic Frameworks-based Materials: Superior Adsorbents for Pollutants Removal from Aqueous Solutions. The Innovation 2021, 2, https://doi.org/10.1016/j.xinn.2021.100076.

16. Yao, L.; Yang, H.; Chen, Z.; Qiu, M.; Hu, B.; Wang, X. Bismuth oxychloride-based materials for the removal of organic pollutants in wastewater. Chemosphere 2021, 273, 128576, https://doi.org/10.1016/j.chemosphere.2020.128576.

17. Wawrzkiewicz, M.; Hubicki, Z. Removal of tartrazine from aqueous solutions by strongly basic polystyrene anion exchange resins. Journal of Hazardous Materials 2009, 164, 502-509, http://doi.org/10.1016/j.jhazmat.2008.08.02.

18. Oancea, P.; Meltzer, V. Photo-Fenton process for the degradation of Tartrazine (E102) in aqueous medium. Journal of the Taiwan Institute of Chemical Engineers 2013, 44, 990-994, http://doi.org/10.1016/j.jtice.2013.03.014.

19. Gupta, V. K.; Jain, R.; Nayak, A.; Agarwal, S.; Shrivastava, M. Removal of the hazardous dye Tartrazine by photodegradation on titanium dioxide surface. Materials Science and Engineering 2011, 31, 1062-1067, http://doi.org/10.1016/j.msec.2011.03.006.

20. Thiam, A.; Zhou, M.; Brillas, E.; Sires, I. Two-step mineralization of Tartrazine solutions: Study of parameters and by-products during the coupling of electrocoagulation with electrochemical advanced oxidation processes. Applied Catalysis B: Environmental 2014, https://doi.org/10.1016/j.apcatb.2013.12.011.

21. Pandey. S.; Do, J.Y.; Kim, J. Fast and highly efficient removal of dye from aqueous solution using natural locust bean gum based hydrogels as adsorbent. International journal of biological macromolecules $\mathbf{2 0 2 0}$, 143, 60-75, https://doi.org/10.1016/j.ijbiomac.2019.12.002. 
22. Fosso-Kankeu, S.; Spiro, E.; Waanders, M. J.; Kumar, F.; Ray, N.; Kang, M. Equilibrium. kinetic and thermodynamic studies of lead ion adsorption from mine wastewater onto MoS2-clinoptilolite composite.

Materials Today Chemistry 2020, 18, 100376, http://doi.org/10.1016/j.mtchem.2020.100376.

23. Gautam, P.K.; Gautam, R.K.; Banerjee, S.; Lofrano, G.; Sanroman, M.A.; Chattopadhyaya, M.C.; Pandey, J.D. Preparation of activated carbon from Alligator weed (Alternentheraphiloxeroids) and its application for tartrazine removal: Isotherm, kinetics and spectroscopic analysis. Journal of Environmental Chemical Engineering 2015, 3, 2560-2568, http://doi.org/10.1016/j.jece.2015.08.004.

24. Gautam, R.K.; Gautam, P.K.; Banerjee, S.; Rawat, V.; Soni, S.; Sharma, S.K.; Chattopadhyaya, M.C. Removal of tartrazine by activated carbon biosorbents of Lantana camara: Kinetics, equilibrium modeling and spectroscopic analysis. Journal of Environmental Chemical Engineering 2015, 3, 9-88, http://doi.org/10.1016/j.jece.2014.11.026.

25. Jibril, M.; Noraini, J.; PohL, S.; Evuti, A.M. Removal of Colour from Waste Water Using Coconut Shell Activated Carbon (CSAC) and Commercial Activated Carbon (CAC). Journal of Engineering Science and Technology 2013, 60, 15-19.

26. Dotto, G.L.; Vieira, M.L.G.; Pinto, L.A.A. Kinetics and Mechanism of Tartrazine Adsorption onto Chitin and Chitosan. Industrial \& Engineering Chemistry Research 2012, 51, 6862-6868, https://doi.org/10.1021/ie2030757.

27. Mourid, El. H.; Lakraimi, M.; Benaziz, L.; Elkhattabi, E. H.; Legrouri, A. Wastewater treatment test by removal of the sulfamethoxazole antibiotic by a calcined layered double hydroxide. Applied Clay Science 2019, 168, 87-95, http://doi.org/10.1016/j.clay.2018.11.005.

28. Elkhattabi, EL.H.; Lakraimi, M.; Berraho, M.; Legrouri, A.; Hammal, R. and El Gaini, L. Acid Green 1 Removal from Wastewater by Layered Double Hydroxides. Applied Water Science 2018, 8, 45, https://doi.org/10.1007/s13201-018-0658-1.

29. Wu, L.; Pan, F.; Liu, Y.; Zhang, G.; Tanga, A. and Atrens, A. Influence of pH on the growth behaviour of $\mathrm{Mg}-\mathrm{Al} \mathrm{LDH} \quad$ films. Surface Engineering 2018, http://doi.org/10.1080/02670844.2017.1382062.

30. Li, Q.; Chen, Z.; Wang, H.; Yang, H.; Wen, T.; Wang, S.; Hu, B.; Wang, X. Removal of organic compounds by nanoscale zero-valent iron and its composites. Sci Total Environ. 2021, 792, 148546, https://doi.org/10.1016/j.scitotenv.

31. Mourid, El. H.; El Mouchtari, El.M.; El Mersly, Benaziz, L.; Rafqah, L. S.; Lakraimi, M. Development of a new recyclable nanocomoposite $\mathrm{LDH}-\mathrm{TiO}_{2}$ for the degradation of antibiotic sulfamethoxazole under UVA radiation: An approach towards sunlight. Journal of Photochemistry \& Photobiology A: Chemistry 2020, $396,112530$.

32. Mourid, E.H.; Lakraimi, M.; Legrouri, A. Removal and Release of the 2,4,5-Trichlorophenoxyacetic Acid Herbicide from Wastewater by Layered Double Hydroxides. Journal of Inorganic and Organometallic Polymers and Materials 2021, 31, 2116-2128, https://doi.org/10.1007/s10904-020-01845-7.

33. Mourid, E.; Lakraimi, M.; Benaziz, L.; Cherkaoui, M. Removal Efficiency of Lipid-regulating Drug Clofibric Acid from the Aquatic Environment by Calcined Anionic Clay ZnAl-CO3. Chemical and Biochemical Engineering Quarterly 2020, 34, 2, 79-92, https://doi.org/10.15255/CABEQ.2020.1797.

34. Rey, F.; Fornés, V.; Rojo, J.M. Thermal Decomposition of Hydrotalcites. An Infrared and Nuclear Magnetic Resonance Spectroscopic Study. Journal of the Chemical Society, Faraday Transactions 1992, 88, 22332238, https://doi.org/10.1039/FT9928802233.

35. Romdhane, D.F.; Satlaoui, Y.; Nasraoui, R.; Charef, A.; Azouzi, R. Adsorption, Modeling, Thermodynamic, and Kinetic Studies of Methyl Red Removal from Textile-Polluted Water Using Natural and Purified Organic Matter Rich Clays as Low-Cost Adsorbent. Journal of Chemistry 2020, https://doi.org/10.1155/2020/4376173.

36. El maguana, Y.; Elhadiri, N.; Benchanaa, M.; Chikri, R. Adsorption Thermodynamic and Kinetic Studies of Methyl Orange onto Sugar Scum Powder as a Low-Cost Inorganic Adsorbent. Journal of Chemistry 2020, 2020, 10, https://doi.org/10.1155/2020/9165874.

37. Boparai, H.K.; Joseph, M.; O'Carroll, D. M. Kinetics and thermodynamics of cadmium ion removal by adsorption onto nanozerovalent iron particles. Journal of Hazardous Materials 2011, 186, 458-465, http://doi.org/10.1016/j.jhazmat.2010.11.029.

38. Giles, C.H.; MacEwan, T.H.; Nakhwa, S.N.; Smith, D. Studies in Adsorption. Part XI. A System of Classification of Solution Adsorption Isotherms, and its Use in Diagnosis of Adsorption Mechanisms and in 
Measurement of Specific Surface Areas of Solids. J. Chem. Soc. 1960, 14, 3973-3993, https://doi.org/10.1039/JR9600003973.

39. Mourid, E.; Lakraimi, M.; Khattabi, E.; Benaziz, L.; Berraho, M. Removal of Textile Dye Acid Green 1 from Wastewater by Activated Carbon. Journal of Materials and Environmental Science 2017, 8, 31213130 .

40. Ashraf, M.W.; Abulibdeh, N., Salam, A. Adsorption Studies of Textile Dye (Chrysoidine) from Aqueous Solutions Using Activated Sawdust. International Journal of Chemical Engineering 2019, 2019, 8, https://doi.org/10.1155/2019/9728156.

41. Adewuyi, A.; Pereira, F.V.; Adewuyi, O.A. Amine modified kaolinite clay from Nigeria: A resource for removing $\mathrm{Cd}^{2+}$ and $\mathrm{Pb}^{2+}$ ions from aqueous solution. Journal of Applied Research and Technology 2019, 17, 78-91, https://doi.org/10.22201/icat.16656423.2019.17.2.798.

42. Yu, S.; Pang, H.; Huang, S.; Tang, H.; Wang, S.; Qiu, M.; Chen, Z.; Yang, H.; Song, G.; Fu, D.; Hu, B.; Wang, X. Recent advances in metal-organic framework membranes for water treatment. 2021, 800, 149662, https://doi.org/10.1016/j.scitotenv.2021.149662.

43. Wang, Q.; Wu, J.; Gao, Y.; Zhang, Z.; Wang, J.; Zhang, X.; Yan, X.; Umar, A.; Guo, Z.; O'Hare, D. Polypropylene/ $\mathrm{Mg}_{3} \mathrm{Al}$-tartrazine $\mathrm{LDH}$ nanocomposites with enhanced thermal stability, UV absorption, and rheological properties. RSC Advances 2013, 3, https://doi.org/10.1039/C3RA44452J.

44. Banerjee, S.; Chattopadhyay, M.C. Adsorption characteristics for the removal of a toxic dye, tartrazine from aqueous solutions by a low cost agricultural by-product. Arabian Journal of Chemistry 2017, 10, S1629S1638, https://doi.org/10.1016/j.arabjc.2013.06.005.

45. Zhu, Y.; Wang, W.; Ni, J.; Hu, B. Cultivation of granules containing anaerobic decolorization and aerobic degradation cultures for the complete mineralization of azo dyes in wastewater. Chemosphere 2020, 246, 125753, http://doi.org/10.1016/j.chemosphere.2019.125753.

46. Klett, C.; Barry, A.; Balti, I.; Lelli, P.; Schoenstein, F.; Jouini, N. Nickel doped Zinc oxide as a potential sorbent for decolorization of specific dyes, methylorange and tartrazine by adsorption process. Journal of Environmental Chemical Engineering 2014, 2, 914-926, http://doi.org/10.1016/j.jece.2014.03.001.

47. Ngah, W.S.W.; Ariff, N.F.M.; Hanafiah, M.A.K.M. Preparation, Characterization, and Environmental Application of Crosslinked Chitosan-Coated Bentonite for Tartrazine Adsorption from Aqueous Solutions. Water, Air, \& Soil Pollution 2010, 206, 225-236, http://doi.org/10.1007/s11270-009-0098-5.

48. Ansari ,R.; Keivani, M.B.; Delavar, A.F. Application of polyaniline nanolayer composite for removal of tartrazine dye from aqueous solutions. Journal of Polymer Research 2011, 18, 1931-1939, https://doi.org/10.1007/s10965-011-9600-z.

49. A. Mittal, L. Kurup, J. Mittal. Freundlich and Langmuir adsorption isotherms and kinetics for the removal of tartrazine from aqueous solutions using hen feathers. Journal of Hazardous Materials 2007, 146, http://doi.org/10.1016/j.jhazmat.2006.12.012.

50. Mittal, A.; Mittal, J.; Kurup, L. Adsorption isotherms, kinetics and column operations for the removal of hazardous dye, tartrazine from aqueous solutions using waste materials-Bottom Ash and De-Oiled Soya, as adsorbents. Journal of Hazardous Materials 2006, 136, 567-578, https://doi.org/10.1016/j.jhazmat.2005.12.037.

51. Mahmoud, M.E.; Abdelfattah, A.M.; Tharwat, R.M.; Nabil, G.M. Adsorption of negatively charged food tartrazine and sunset yellow dyes onto positively charged triethylenetetramine biochar: Optimization, kinetics and thermodynamic study. Journal of Molecular Liquids 2020, 318, 114297, http://doi.org/10.1016/j.molliq.2020.114297.

52. Aarfane, A.; Salhi, A.; El Krati, M;. Tahiri, S.; Monkade, M.; Lhadi, E.K.; Bensitel, M. Kinetic and thermodynamic study of the adsorption of Red195 and Methylene blue dyes on fly ash and bottom ash in aqueous medium. Journal of Materials and Environmental Science 2014, 5, 1927-1939.

53. Marangoni, R.; Bouhent, M.; Taviot-Guého, C.; Wypych, F.; Leroux, F. Zn ${ }_{2} \mathrm{Al}$ layered double hydroxides intercalated and adsorbed with anionic blue dyes: A physico-chemical characterization. Journal of Colloid and Interface Science 2009, 333, 120-127, https://doi.org/10.1016/j.jcis.2009.02.001. 